\title{
Regional AET indicating oasis water consumption and groundwater dynamics under a background of climate change
}

\section{CURRENT STATUS: UNDER REVISION}

Carbon Balance and Management $\triangle B M C$

Lei $\mathrm{Wu}$

Lanzhou University

Li Changbin

च licb@lzu.edu.cnCorresponding Author

Xuhong Xie

Lanzhou University

Zhibin $\mathrm{He}$

Northwest Institute of Eco-Environment and Resources

Wanrui Wang

Xinjiang Institute of Ecology and Geography

Yuan Zhang

Lanzhou University

Jianmei Wei

Lanzhou University

Jianan Lv

Lanzhou University

\section{DOI:}

$10.21203 / \mathrm{rs} .2 .20566 / \mathrm{v} 1$

\section{SUBJECT AREAS}

\section{Environmental Engineering}

\section{KEYWORDS}

Oasis water utilization, regional AET, groundwater responses, the Shiyang River Basin 
Abstract

Background: Development of agriculture-dominated socio-economy have led to remarkable increase of water consumption in arid regions of the world. Frequent over-exploitation of water resources resulted in widely environmental degradation in the water-scarce and eco-fragile area, especially in China's inland river basins. The Shiyang River Basin (SYRB) is the one where the most contradictive situation was found between socio-economic development and environmental sustainability in recent decades. In this study, a case study clarifying groundwater responses to intensive oasis water utilization was conducted during the time period from 1981 to 2010.

Result: Regional AET was stepwise regressed with observed series of T, P and NDVI, the accuracy was found satisfactory. Module analysis revealed that the continuous warming had facilitated the AET rather than the other two factors ( $\mathrm{P}$ and $\mathrm{NDVI}$ ). The 30-year statistics revealed that total volume of oasis water utilization far exceeded mountainous discharges in the SYRB. Local abstractions offset the insufficiency and resulted in considerable drawdown of groundwater level. Dynamics of groundwater were found remarkably influenced by land surface water division, oasis scale and water consumption. Driven module calibrated upon regional averages of the above variables, suitable scale of the oasis was quantitatively discussed. Results revealed that the near-complete development of mountainous discharges, along with the over-exploitation of groundwater, have brought about degradation of the underground water system. Groundwater level drawdown showed annual rates of $0.17 \mathrm{~m} / \mathrm{a}$ and 0.31 m/a in the middle and lower areas, respectively, during the time period from 1981 to 2010 .

Conclusions: Overexploitation of water resources and its negative consequences for regional hydrology and ecology in arid regions should be considered as a warning for pursuing economic wellbeing at the expense of the environment. Given the huge water demand for oasis survival and the background of climatic warming, reduction of arable scale combined with water transfer from outside should be conducted. This study serves as a 30-year case example when above contradictions presented remarkably in inland river systems in the arid northwestern China.

Full-text

Due to technical limitations, full-text HTML conversion of this manuscript could not be completed. 
However, the manuscript can be downloaded and accessed as a PDF.

Figures

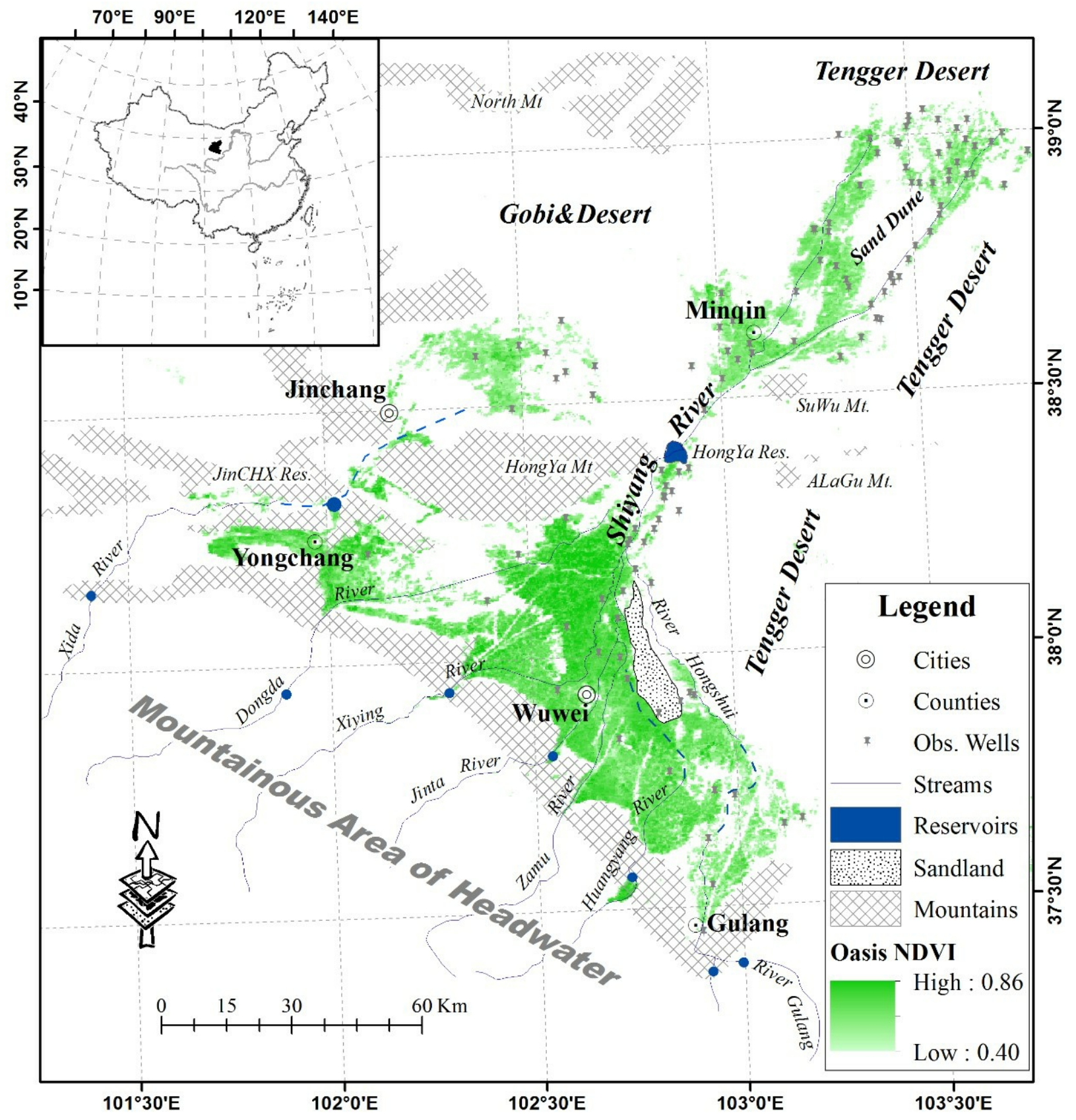

Figure 1

Location map and oasis distribution in the SYRB. The basin is divided into areas in upper,

middle and lower reaches according to regional hydrogeomorphology. Oasis are mainly

located in areas of the latter two reaches, that in the north of the Hongya Res. is defined as

in the lower reaches (administratively belonging to Minqin district), others are defined as in 
the middle reaches (administratively belonging to districts of Wuwei, Jingchang and Yongchang). Note: The designations employed and the presentation of the material on this map do not imply the expression of any opinion whatsoever on the part of Research Square concerning the legal status of any country, territory, city or area or of its authorities, or concerning the delimitation of its frontiers or boundaries. This map has been provided by the authors.

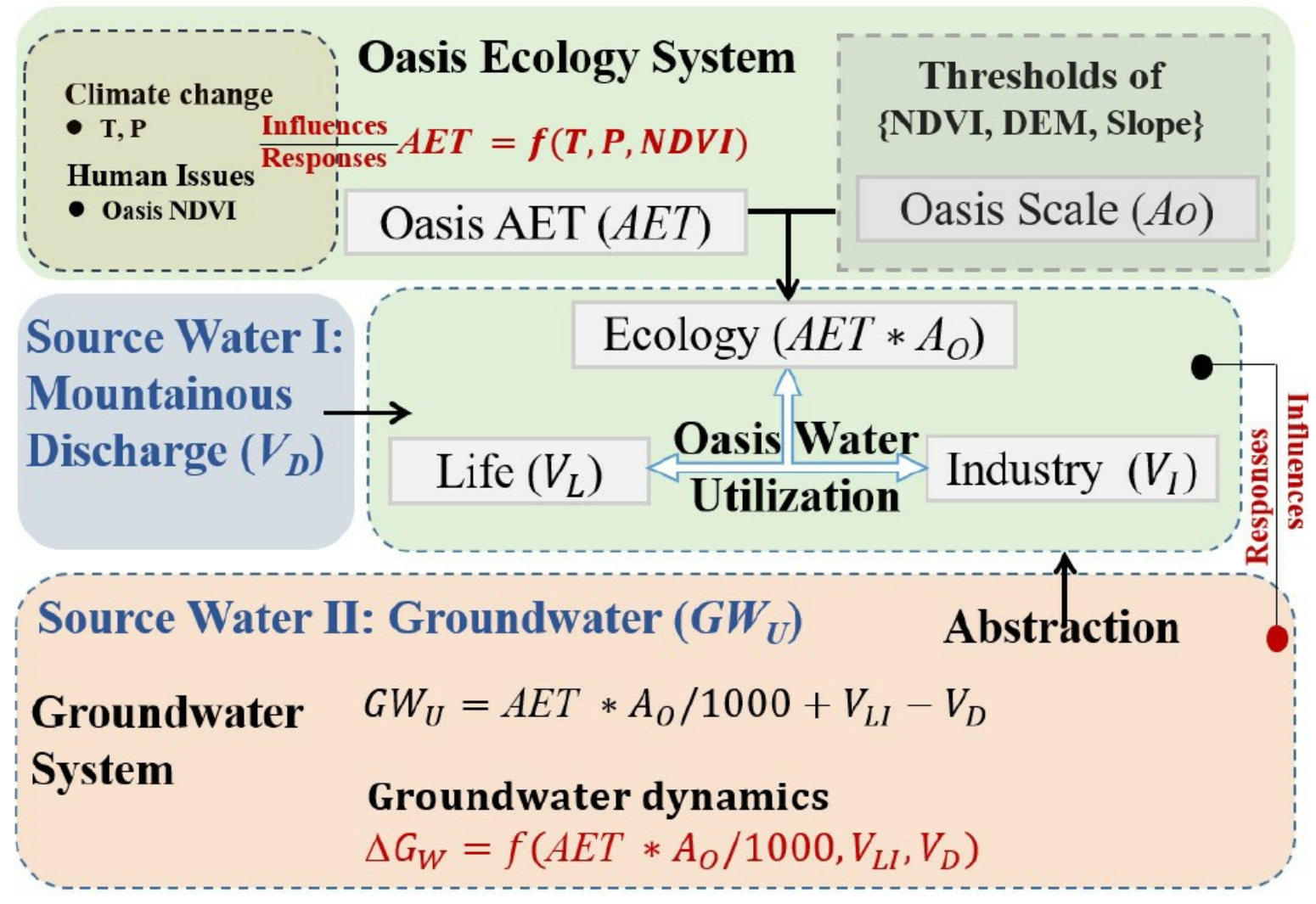

Figure 2

The coupling framework determining groundwater dynamics responding to oasis water consumption through regional AET. 


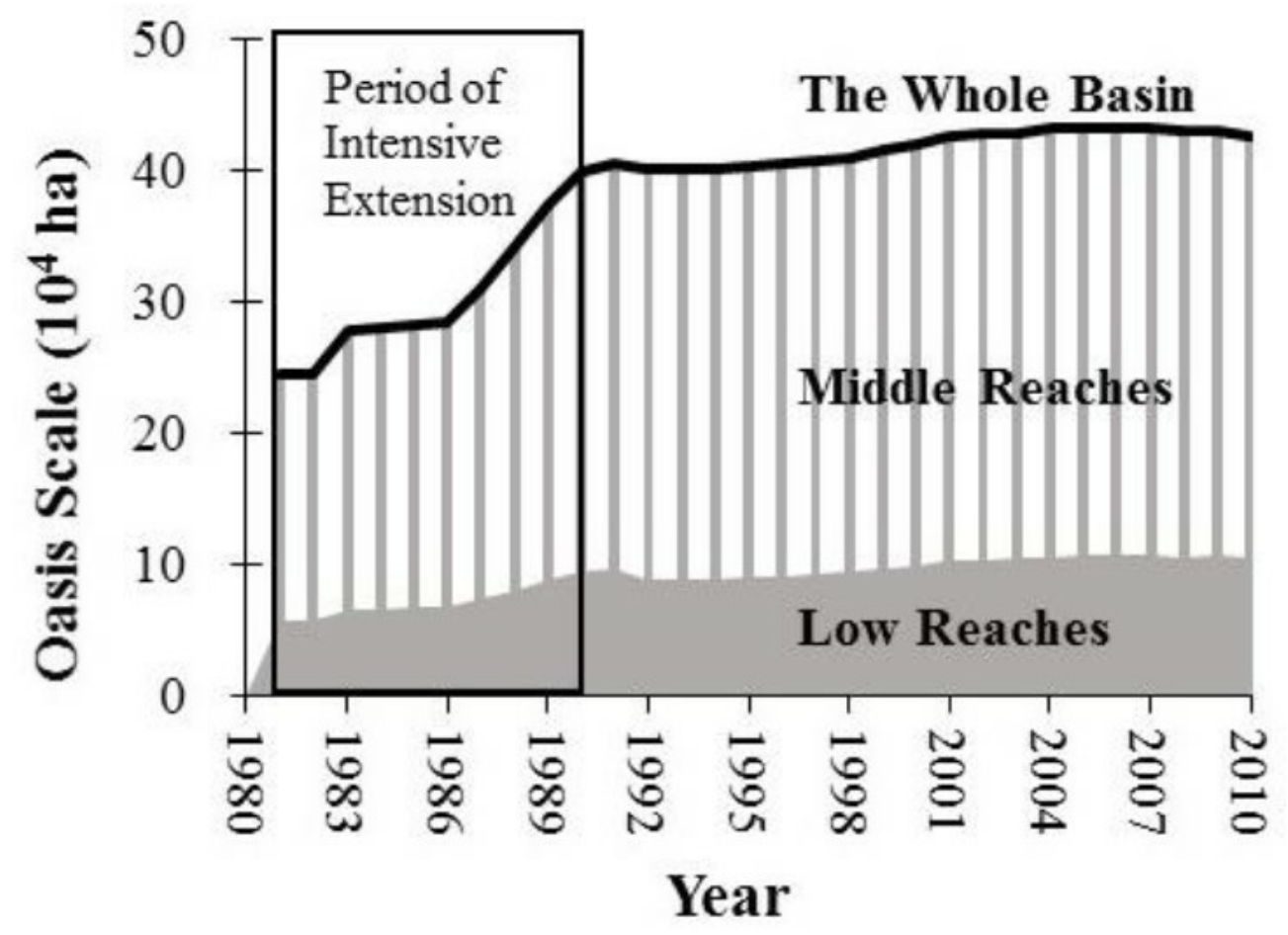

Figure 3

Changes of oasis scale in the SYRB from 1981 to 2010. Correlation between AET and climatic and vegetative factors 


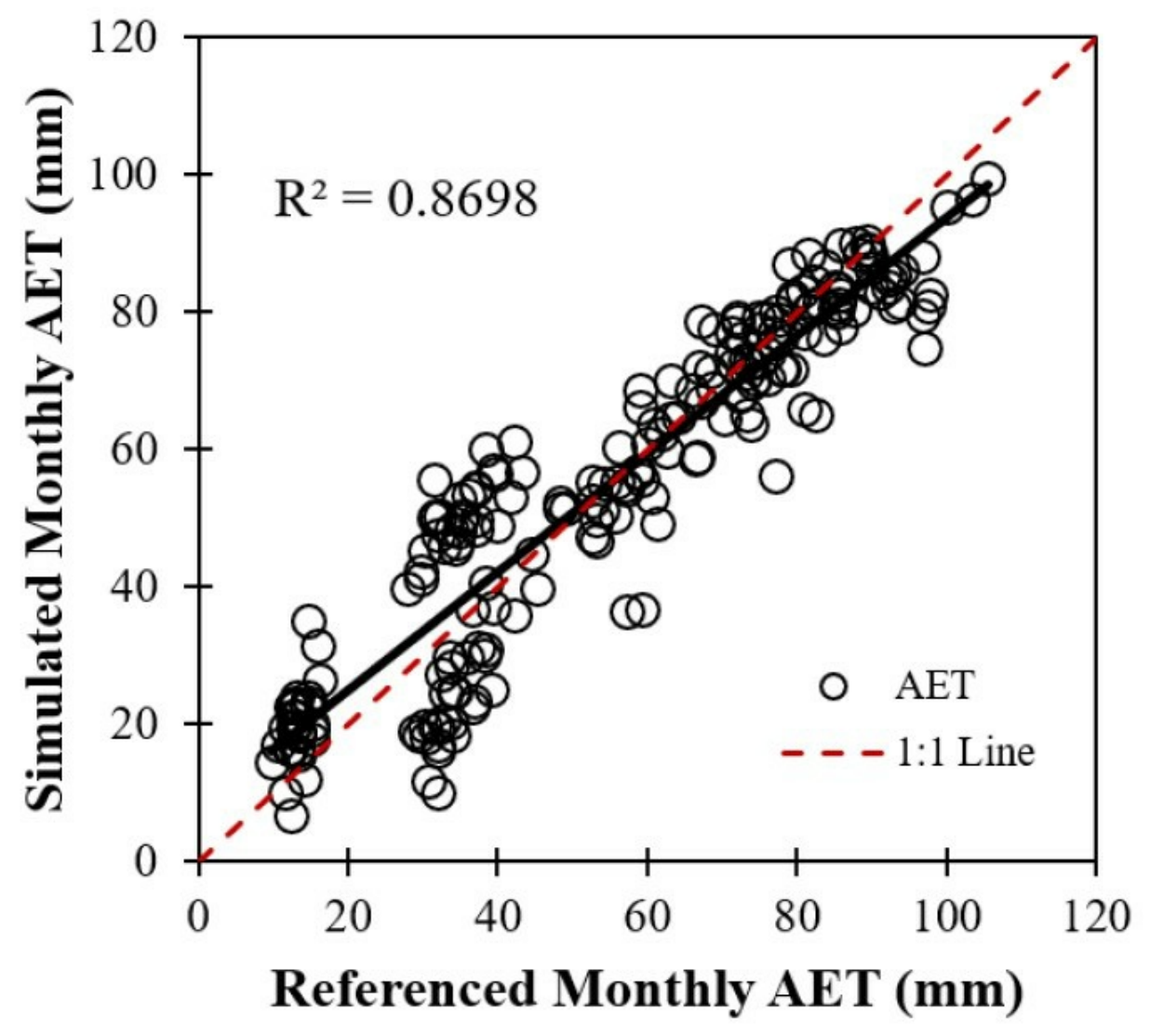

Figure 4

Calibration of the climate $\&$ vegetation factors driven regional AET. 


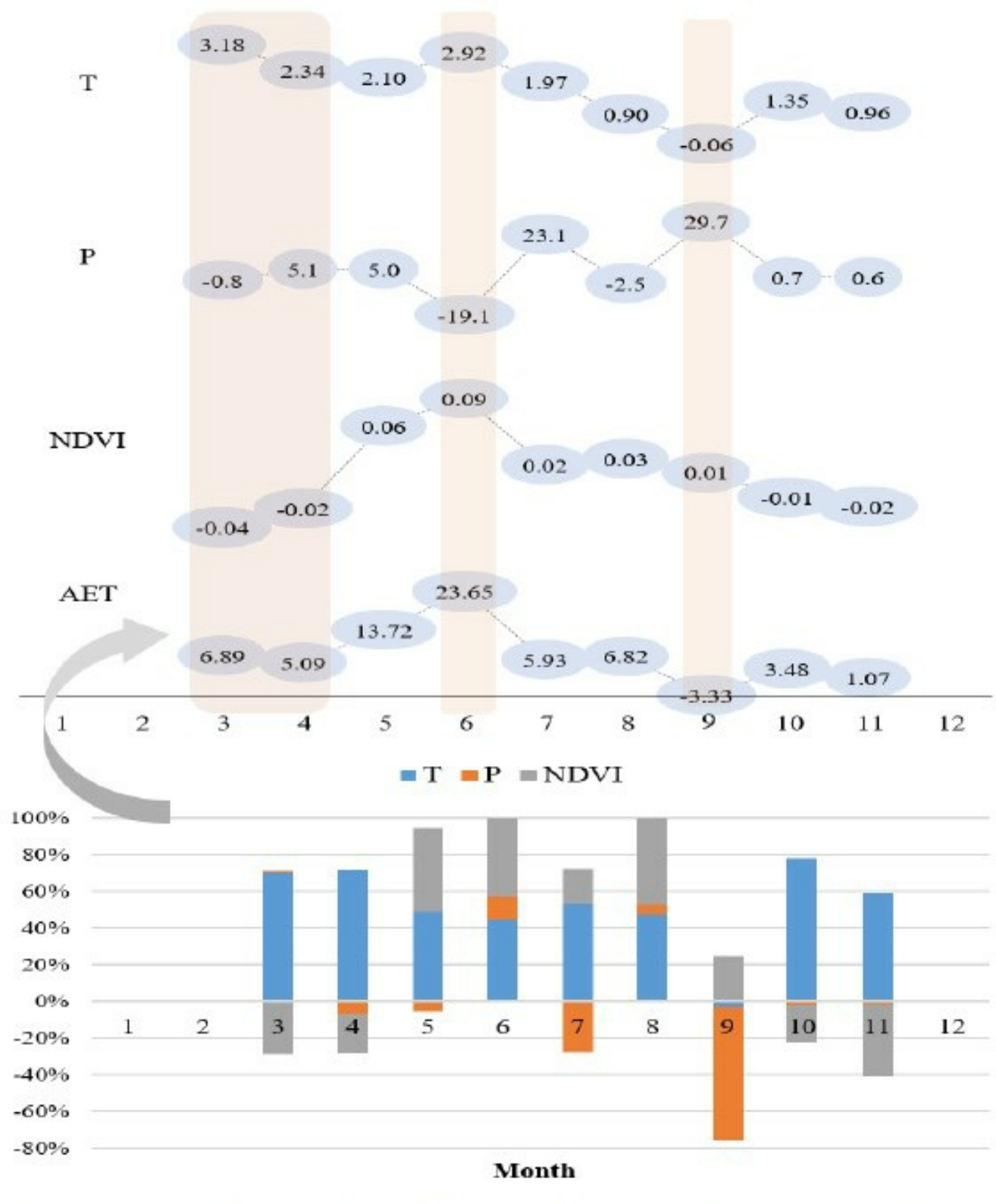

Figure 5

Monthly variation of each factors and their contributions to AET variation. The positive and negative signs represent the enhanced or weakened effects. 


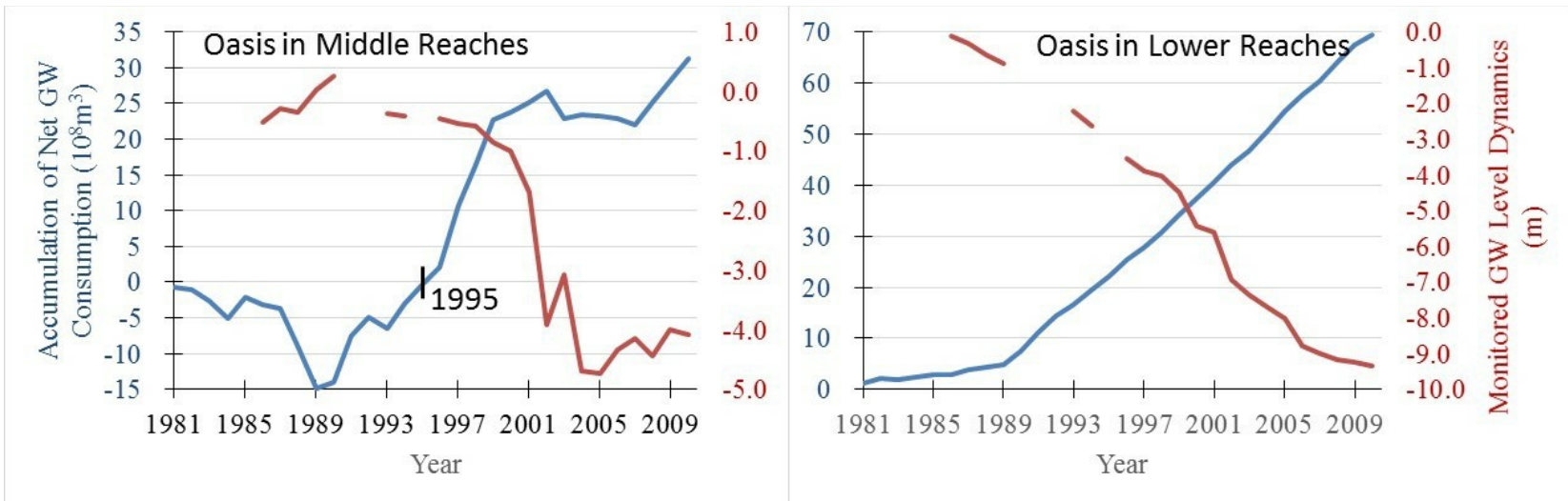

Figure 6

Trends of accumulation of net groundwater consumption and groundwater level dynamics. Inverse trends of the two were found in oasis areas in the middle and lower reaches of the SYRB.

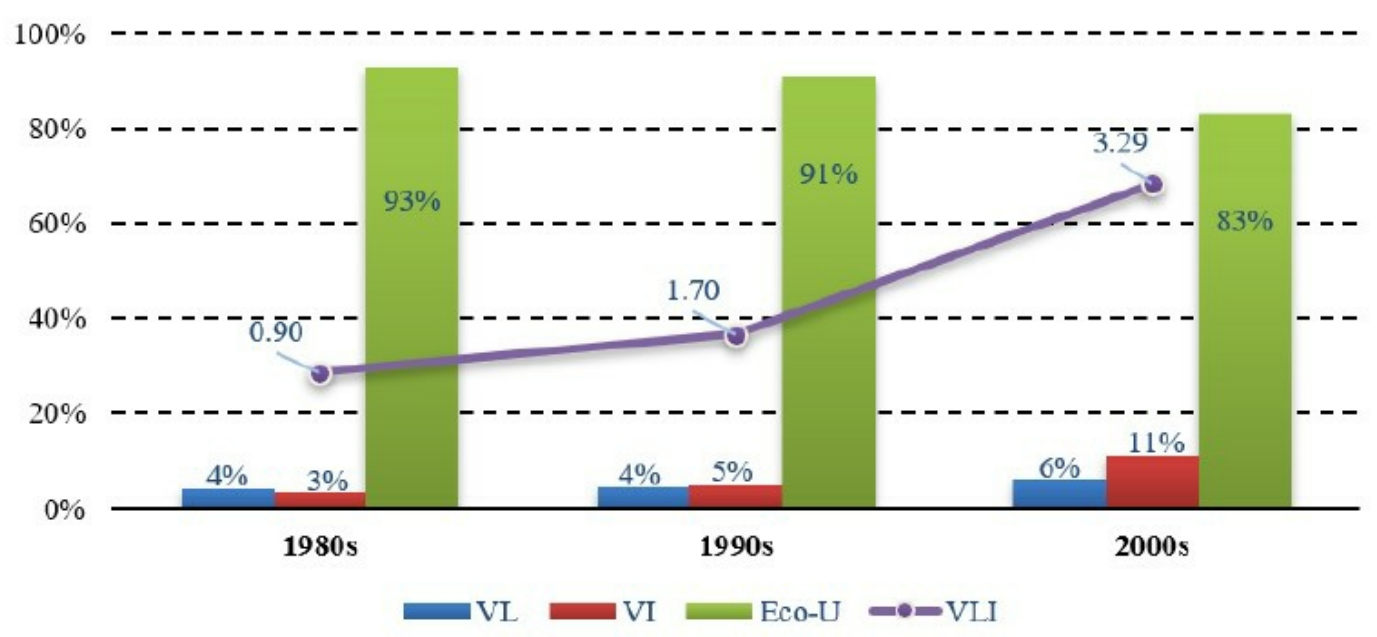

Figure 7

Percentages of water used for different purposes in the SYRB. (Legend: VL, VI and Eco-U represent water use by life, manufacturing industry and oasis consumptions, respectively. VLI shows the variation of life and industry water use in different decades (in 108m3).) 


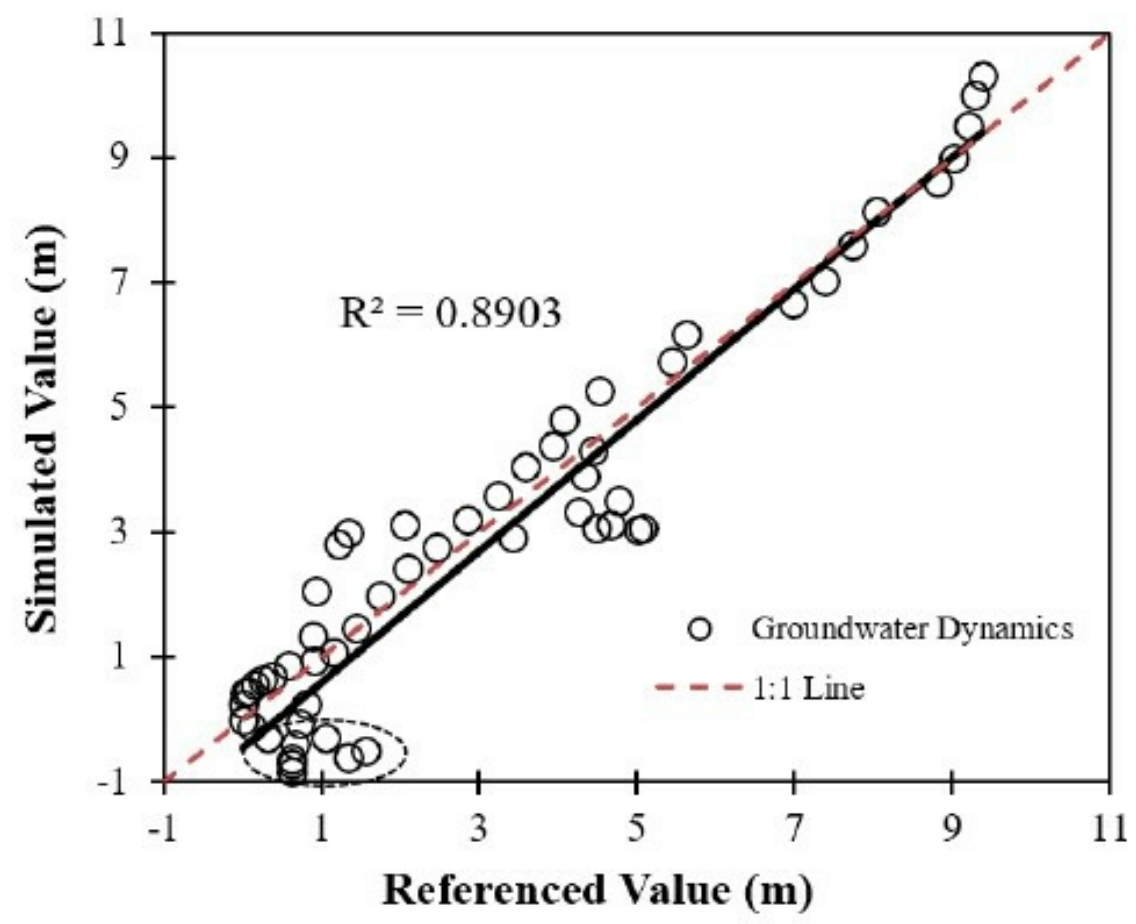

Figure 8

Calibration of the groundwater dynamics driven by oasis AET, scale and mountainous discharges. 


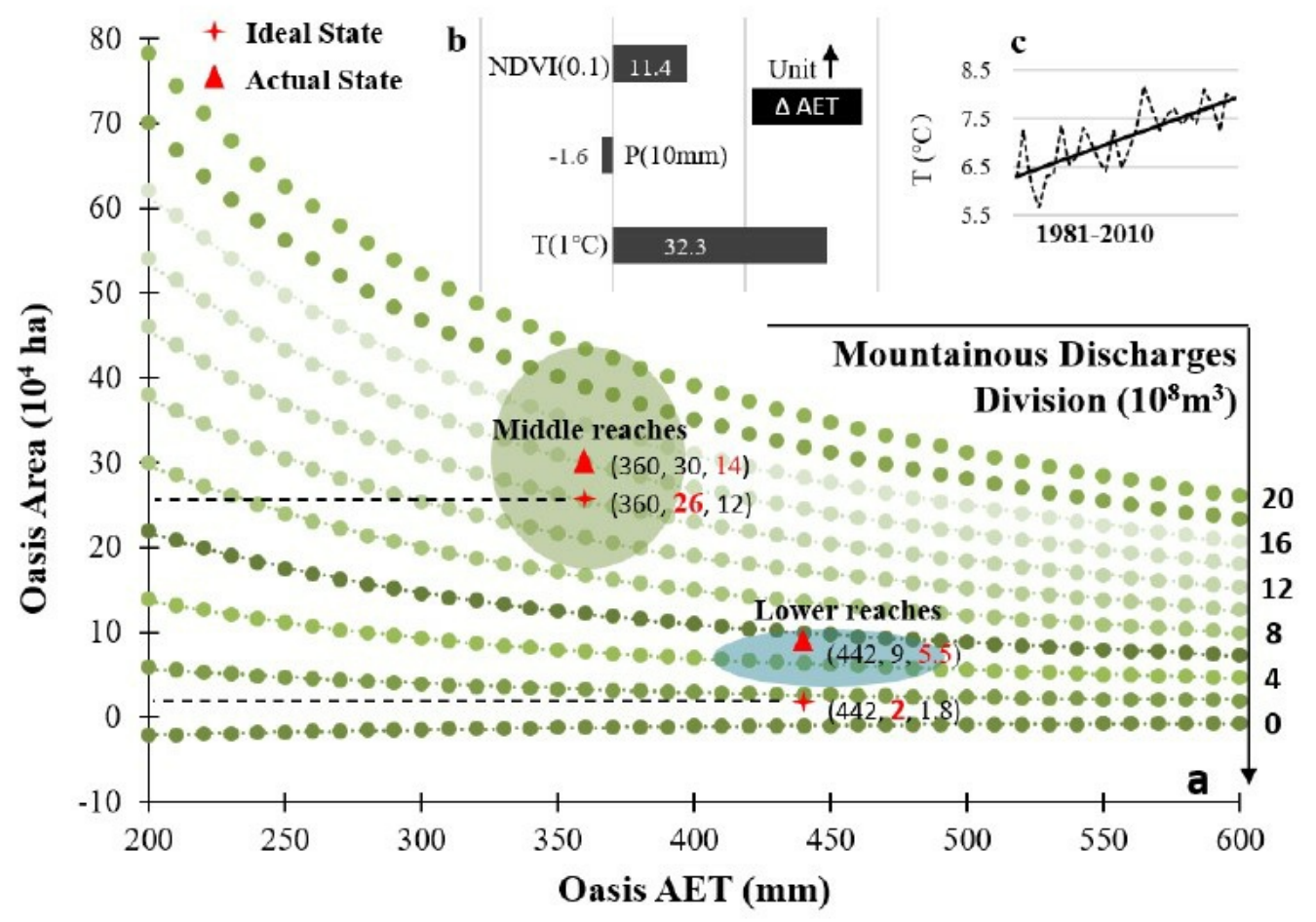

Figure 9

Ideal oasis water utilization based on considering oasis area, AET and mountainous discharges (a). Regional AET variations due to unit changes of influential factors (b) and increasing of air temperature in the SYRB during the time period from 1981 to 2010. 


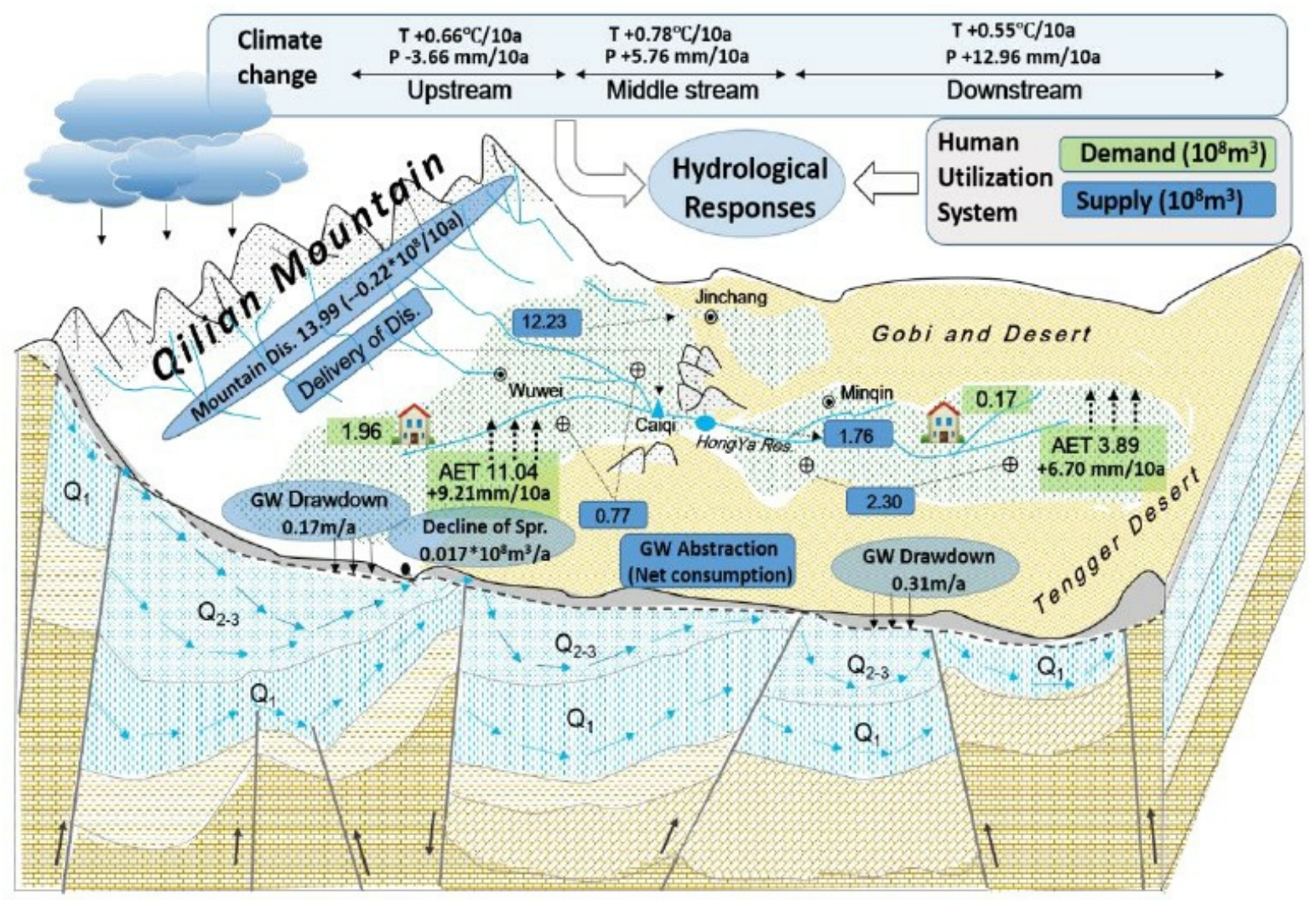

Figure 10

Conceptual illustration of groundwater dynamics corresponding to regional climate change and oasis water consumption across the SYRB, during the time period from 1981 to 2010. 